\title{
An Aggregate Model for the Prediction of Electricity Demand: Calabar South in Nigeria as Case Study.
}

\author{
${ }^{1}$ Ekpenyong, E.E, ${ }^{2}$ Bam, M.E and ${ }^{3}$ Anyasi, F.I \\ ${ }^{1,2}$ Department of Electrical/Electronic Engineering, Cross River University of Technology, P.M.B 1123, \\ Calabar. Nigeria. \\ ${ }^{3}$ Department of Electrical and Electronics Engineering, Ambrose Alli University, P.M.B 14, Ekpoma, Edo State,
} Nigeria.

\begin{abstract}
This study examines three levels of models; the Basic empirical model, the Phi ( $\phi)$ model and the composite model for the prediction of electricity demand in Calabar South Local Government Area of Cross River State, Nigeria. Data were collected from primary sources which included, households, industries etc. The study reveals that the total electricity installed in Nigeria is about 9,000MW at which above 105MW is supplied to Calabar District and 16MW supplied to Calabar South Local Government Area. By 2015 it is expected to be 64.200MW. The developed model is capable of forecasting electricity demand on a sectional basis as well as on zonal basis. This would provide necessary planning data for electricity generation, transmission and distribution.
\end{abstract}

\section{Introduction}

Electricity constitutes an essential impact in the development process. It is the biggest operational problem facing industries in Nigeria. Available information shows that Nigeria's total installed capacity for electricity is about $5998.19 \mathrm{MW}$ by 1998 out of which $2761.47 \mathrm{MW}$ is available for distribution. For over twenty years prior to 1999, the power sector did not witness substantial investment in infrastructural development. During that period, new plants were not constructed and the existing ones were not properly maintained, bringing the power sector to a deplorable state. In 2001, generation went down from the installed capacity of about 5,600MW to an average of about 1,750MW, as compared to a load demand of 6,000MW. As at July 2010, Nigeria's total installed capacity was about 10,000MW with independent power producers (IPPs) contributing about $1,700 \mathrm{MW}$ of the capacity out of which an average of 3,800MW was available for distributing and about 100MW was supplied to Calabar district. Electricity supply falls far below the real and unsuppressed demand. Several efforts have been made by the federal government, the state government and the private sector to boost electricity supply. It is however important to be able to forecast the real and unsuppressed demand to ensure adequate planning [1]. In Nigeria, the generation of electricity started in 1896 when the first generating plant was installed in the city of Lagos by the colonial government, later the Local Municipal Authorities set up other electricity undertakings in different parts of the country. All the stations were thermal using either coal or diesel. By 1950, the Federal Government unified all much undertaking under the electricity cooperation of Nigeria $(\mathrm{ECN})$. The ECN was charged with the responsibility of electricity generation [2]. Output was noticed by 1960 when the electricity power demand rose by $20 \%$ per annum. This led to the establishment of the Niger Dams Authority (NDA) in 1962. This body developed hydroelectric power from 1968; the Kainji power Station was commissioned with an installed capacity of 320MW. The NDA generated power and sold it to the ECN for distribution to consumers. The arrangement continued till 1969 when the merging of NDA and ECN became an issue for consideration. The merger finally took place and culminated in the establishment of the National Electric Power Authority (NEPA) according to the government decree No.24 of 1972 which states as follows: It shall be the duty of NEPA to develop and maintain an efficient coordinate and economical system of electricity supply for all parts of the federation or as the Authority may direct and for this purpose [3].

i. To generate or acquire supply of electricity

ii. To provide built supply of electricity for distribution within or outside Nigeria and

iii. To provide supply of electricity for consumers in Nigeria and as may from time to time be authorized by the authority.

Hence, NEPA got the exclusive right over planning, designing, construction and maintenance of an efficient, coordinate and economical system of electricity supply to all parts of federation and outside [4]. It has two modes of generating electric power; the hydroelectric and the thermal type. The thermal is subdivided into gas and steam thermal generating stations. The hydroelectric power generating stations are the Kainji, Jebba and Shiroro stations with generating capacities of 760MW from 8 units, 540MW from 6 units, and 600mW from 4 units respectively. The gas thermal stations are the Delta, Afam and Sapele stations with generating capacities of 912MW for 20 units, 700MW from 17 units, and 300MW from 4 units respectively. The steam 
thermal station are the Sapele, Egbin, Ijora, Ajabute and Oji River Power station with generating capacities of 72MW from 6 units, 132MW from 6 units, 60MW from 4 units, 110MW from 6 units, 1320MW from 6 units respectively. The system is connected into a grid and their power poles are in 2 zones. NEPA had five zones through which this system is connected namely Lagos, Oshogbo, Enugu Bauchi and Kaduna.

\section{The Overview Of Electricity In Nigeria}

The organization responsible for electricity production and supply in Nigeria is the Power Holding Company of Nigeria (PHCN) formally known as National Electric Power Authority (NEPA). Nigeria has a total of about $10,000 \mathrm{MW}$ of installed generating capacity. However, the country is only able to generate about 3 , $8000 \mathrm{MW}$ because most facilities have been poorly maintained. The country has proven gas reserves and around $8,000 \mathrm{MW}$ of hydro power plant development had been planned [5]. Nigeria had planned to increase access to electricity throughout the country to about approximately $15000 \mathrm{~km}$ of transmission lines, as well as distribution facilities [6].

Nigeria power sector has high energy losses $(30 \%-35 \%)$ from generation to building a low collection rate $(75-80 \%)$ and low access to electricity by the population $(36 \%)$. There is insufficient cash generation because of these inefficiencies and PHCN is consequently reliant on few subsidies and funding of capital projects by the government.

At present only $30 \%$ of rural households and $60 \%$ of the country's total population have access to electricity. The Nigerian energy commission and the solar Energy society of Nigeria have been tasked with generating a solar power solution for the remote rural dwellers not served by the National Power grid. Nigeria expects electricity to neighboring Niger via a 132KV interconnection constructed in 1976.

The Nigeria government is in the process of privatizing existing facilities.

The country's electrical power demand is high but actual generation is considerably below demand. As a result, Nigeria has experienced an energy supply crisis in recent years. Electricity statistics in Nigeria lagged behind that of other comparative countries even in Africa. The comparative figure of Nigeria is equivalent to around $162 \mathrm{KWH}$ per capital. Comparative figures for the other countries in Africa are South Africa, 4,00KWH, Libya, 3347KWH; Algeria, 929KWH and Ghana with 286KWH. [3]

Importers of electricity generators continue to flood the Nigerian market with substandard generators that pack up before the actual life span. The generator industries in Nigeria are one of the few industries that have not huge foreign exchange outflows associated with generators imports, the huge cost of running these generators have brought significant negative social, economic and environmental impacts on Nigerians. All categories of business spend significant proportion of their start-up costs of acquisition of generators, while maintaining acquisition of generators constitute an important operational costs. In 2005, Nigeria was reported to be the largest importer of generators in Africa, spending 152 million on generator imports. This figure includes only diesel fixed generators exclude imports from countries outside Europe USA and Japan, [7]..

\section{Electricity Demand In Nigeria}

The economic situation of the country has a direct reflection on the basic infrastructures and services like electricity supply, which is the engine for industrial growth. Dramatic upturn of the economy will cause increase in electricity consumption nationwide. The reliability and annual consumption of electricity of every nation is an index of socio-economic development. Electricity is so vital to modern-day living that there can be no meaningful development without it, $[8,9]$

In Nigeria, the household sector is the largest consuming sector in economy. It accounts for about a quarter of total commercial energy and over $90 \%$ of traditional fuels, especially firewood. It also accounts for $62 \%$ and $65 \%$ of the total delivered final energy in 2005, 2007 and 2009 respectively, see table 1.

Table: 1 Sartorial final energy consumption (\%) [3].

\begin{tabular}{|l|l|l|l|}
\hline Sector/year & 2005 & 2007 & 2009 \\
\hline Domestic & 62.0 & 65.0 & 65.0 \\
\hline Industry & 15.0 & 15.0 & 11.3 \\
\hline Public & 22.0 & 19.0 & 20.2 \\
\hline Agriculture & 0.4 & 0.4 & 0.5 \\
\hline Recreational & 0.4 & 0.6 & 2.5 \\
\hline
\end{tabular}

In the last two decades, commercial energy consumption has risen tenfold in Nigeria and urban household energy consumption as a percentage of the total commercial energy consumed is high. This trend is expected to continue in the future. Some of the factors responsible for this trend include increasing population pressure, rapid industrial and economic development, increase urbanization and relentless efforts of rural development. 
Projected electricity demand has been translated into demand for grid electricity and peak demand on the bases of assumptions made for transmission and distribution losses, auxiliary consumption, load factor and declining non-grid generation, [10].

Demand side management strategies are a way of reaching the demand for electricity. It is the process of managing consumption of energy to optimize the available and planned generation resources. It is defined as an actual taken on the side of the customer to change the amount or thing of energy consumption. It involves planning, implementing and monitoring activities of electricity utilities that are designed to encourage consumers to modify their level and pattern of electricity usage. It refers only to energy and load shape modifying activities undertaken in response to utility administered programs.

In this study, aggregate means total amount made up of smaller amount that are collected together. This implies that in the developed models, the total demand of electricity in Calabar South Local Government will be made up of various sectional and zonal electricity demands in the Local Government.

This study covers the domestic, agricultural, industrial, public, and recreational sectors of each zone or Ward and was carried out within the period of March and October 2012 and with respect to the developed model by the author and Ward 12 was use as a case study or the base of the study.

\section{Model Development}

In order to develop a model for the purpose of forecasting electricity demand for Calabar South Local Government, the Local Government has been divided into wards (12 wards). The sectors of the economy have also been divided into five, namely Domestic, Industrial, Agricultural, Recreational and Public Sectors.

For the purpose of developing the models, total electricity demand is defined as follows:

Electricity Demand = DOM. + IND. + PUB. + AGR. + REC.

Three levels of models were developed. The three models include:

i. $\quad$ The Basic Empirical Model

ii. $\quad$ The Phi (ф) model

iii. The composite model

\section{Basic Empirical, Mode}

The first level which is the basic empirical model involved the use of real data collected from the field and through the use of questionnaires.In this level of modeling, it is possible to forecast electricity demand making use of data collected directly from the field or from existing data bank, such as projected populated area of Calabar South Local Government by ward, number of hotels, hospitals and industries in the ward [8]

Such data collection efforts required for the Basic empirical model are however not beyond the capability of Power Holding Company of Nigeria (PHCN) who are the main beneficiary of this study.

\section{PHI ( $\square$ ) MODEL}

\section{BASIC CONCEPT}

The phi $(\phi)$ model seeks to determine the total electricity demand for the local government by selecting a ward as a case study and then apply suitable factors to predict electricity demand in the other wards.

The total electricity demand $\mathrm{E}$ is given as:

$$
\mathrm{E} \quad=\quad \sum \Sigma \text { ej } \phi \mathrm{m} .
$$

Where $\mathrm{ej}=$ electricity demand for the case study ward in the $\mathrm{j}^{\text {th }}$ sector.

$\begin{array}{llll}\mathrm{j} & = & 1 & \text { Domestic Sector } \\ \mathrm{j} & = & 2 & \text { Industrial Sector } \\ \mathrm{j} & = & 3 & \text { Public Sector } \\ \mathrm{j} & = & 4 & \text { Agricultural Sector } \\ \mathrm{j} & = & 5 & \text { Recreational Sector } \\ \text { oij } & = & \{\phi 1, \text { dom; } \phi 1, \text { ind; } \phi 1, \text { pub; } \phi 1, \text { agric; } \phi 1, \text { rec }\}\end{array}$

Where

$\phi 1$, dom $=$ Population of ward relative to base ward

$\phi 1$, ind $=$ Level of industrial development of ward relative to base ward.

$\phi 1$, pub $=$ Level of development of Public facilities in ward relative to base ward.

$\phi 1$, rec $=$ Level of development of recreational facilities in ward relative to base ward

$\phi 1$, agr $=$ Level of agricultural facilities in ward relative to base ward. 


\section{DETERMINATION OF}

The various values of $\phi$ are estimated as follows:

\section{a. DOMESTIC DEMAND $\square$ DOM}

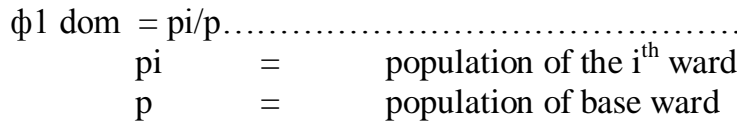

b. INDUSTRIAL DEMAND, $\square$, IND.

$\phi 1$ ind $=\{(n s j$, ej + nm, em + niei $) /($ ns.es + nm.em + ni.ei $)\}$

naj $=$ Number of small scale industries in the $\mathrm{i}^{\text {th }}$ ward

$\mathrm{ni}=$ Number of small scale industries in the base ward.

$\mathrm{Nmi}=$ Number of medium scale industries in the $\mathrm{i}^{\text {th }}$ ward

$\mathrm{Nm}=$ Number of medium scale industries in the base ward.

$\mathrm{Nli}=$ Number of large scale industries in $\mathrm{i}^{\text {th }}$ ward.

$\mathrm{Nl}=$ Number of large scale industries in the base ward.

Eas $=$ Electricity demand estimated for an average small scale industry in the base ward.

Eam $=$ Electricity demand estimated for an average medium scale industry in the base ward.

Eal $=$ Electricity demand estimated for an average large scale industry in the base ward.

c. PUBLIC FACILITY DEMAND, $\square$, PUB.

In the determination of $\$ 1$ pub, number of hotels in ward is used as a measure of public facilities. The various hotels are rated as per international rankings by stars e.g. 3-star hotel, 5-star hotel etc.

Although, hotels are not the only type of public facilities that use electricity, preliminary investigations at the base ward shows a direct correlation between the hotels and the other public facilities. Consequently, Equation 6 is used to determine the $\phi 1$, pub. for the various wards.

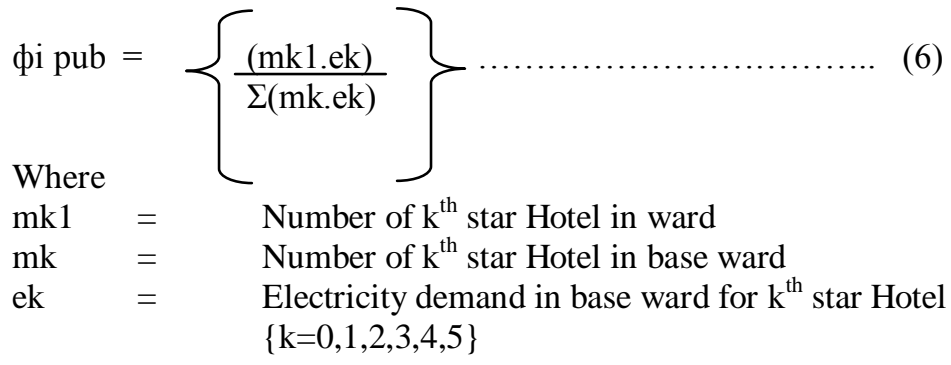

\section{d. AGRICULTURAL DEMAND}

Electricity is needed for food storage, food preservation, livestock irrigation and lighting. The level of mechanization will not necessarily affect the demand of electricity. It will only affect the demand for other forms of electricity such as diesel etc. However, the potential electricity demand as a result of agriculture can be fairly estimated based on the number of mechanized farms in ward and the median electricity demand per farm. The demand for subsistence agriculture is assumed negligible. Therefore, agric is estimated using Eqn. (7)

$\phi$, Agric $=\mathrm{A}_{1} / \mathrm{A}$.

Where

$\mathrm{A}_{1} \quad=\quad$ Total land area of mechanized farms in ward

A $\quad=\quad$ Total land area of mechanized farms in the base ward.

Admittedly, there is a need to seek for a better index for $\phi$, agric which is not only based on land area of mechanized farms but it accounts for the degree of mechanization of such farms.

\section{a. RECREATIONAL DEMAND, $\square$ 1, REC}

Electricity demand for recreation depends very much on the level of citizens. The recreational centers referred to included sports, cultural centre's, cinemas, club houses etc. but does not include star rated hotels which in this study is classified as a public facility. The level of enlightenment can be linked with the rate of illiteracy. The National Population Commission has the literacy index for every ward of the local government. Equation 8 can be used to determine $\phi \mathrm{I}$ rec.

фI rec. $=\mathrm{Li} / \mathrm{L}$

Where

$\mathrm{Li}=\quad$ literacy rate for ward 
$\mathrm{L} \quad=\quad$ literacy rate for base ward.

\section{THE COMPOSITE MODEL}

The composite model does not depend on comparison of other wards with base ward. Rather, electricity demand for a ward is estimate directly using other factors as given below. The previously used forms like domestic, industrial, public, agricultural and recreational sectors will still be used in developing the composite model.

\section{DOMESTIC ELECTRICITY DEMAND}

In this model, the domestic electricity demand is a function of population as well as level of convenience judged by the average electricity demand for a ward.

$\mathrm{DOM}=\mathrm{Pi} \mathrm{E}_{\mathrm{d}}$

Where

$E_{d}=$ the domestic electricity demand of an average person per day in ward.

$\mathrm{Pi}=$ the total population of the base ward.

\section{INDUSTRIAL ELECTRICITY DEMAND EQUATION}

Industrial demand is a function of the number of industries in a given zone. Industries are categorized into small, medium and large. Standard definition of the categories of industries is based on management structure, capital investment on machinery and equipment and the number of employees. However, in this study, categorization was done on the basis of electricity demand by industries as follows.

$\mathrm{IND}_{1}=\mathrm{N}_{1} \mathrm{E}_{1}+\mathrm{N}_{2} \mathrm{E}_{2}+\mathrm{N}_{3} \mathrm{E}_{3}$

Where:

$\mathrm{N}_{11}=$ Number of small scale industry (type 1 ) in $\mathrm{i}^{\text {th }}$ ward

$\mathrm{N}_{21}=$ Number of medium scale industry (type 2) in $\mathrm{i}^{\text {th }}$ ward.

$\mathrm{N}_{31}=$ Number of large scale industry (type 3 ) in $\mathrm{i}^{\text {th }}$ ward

$E_{11}=$ Electricity demand for small scale industries (types 1 ) in the $i^{\text {th }}$ ward.

$\mathrm{E}_{12}=$ Electricity demand for medium scale industries (type 2 ) in the $\mathrm{i}^{\text {th }}$ ward

$\mathrm{E}_{13}=$ Electricity demand for large scale industries (type 3 ) in the $\mathrm{i}^{\text {th }}$ ward.

\section{PUBLIC ELECTRICITY DEMAND EQUITATION}

Public electricity demand is a function of land area in a given zone. $\mathrm{PUB}=\mathrm{Ai} / \mathrm{Epi}$

Where

$\mathrm{Ai}=$ land area ward

Epi $=$ Average public electricity consumption per area for ward.

AGRICULTURAL ELECTRICITY DEMAND EQUITATION

$\mathrm{AGR}_{1}=$ Nfi Eai

Electricity demand for farms in a zone is given as.

Where

$\mathrm{Nfi}=$ Number of Agriculture farm in ward

Efi $=$ Electricity consumption per agric farm ward .

\section{RECREATIONAL ELECTRICITY DEMAND EQUATION}

Recreational electricity demand is a function of the number of recreational centers and the level of enlightenment in a given zone.

$\mathrm{REC}_{\mathrm{i}}=\mathrm{R}_{\mathrm{i}} \mathrm{ER}_{\mathrm{i}}$

$\mathrm{R}_{1}=$ number of recreational centers

$\mathrm{ER}=$ Electricity demand per recreational centre for ward

\section{TOTAL ELECTRICITY DEMAND EQUATION}

Total electricity demand equation is the addition of all the demand equations for domestic, industrial, public, agricultural and recreational sectors.

The main difference between the basic empirical models is that the basic empirical model is entirely based on actual data while the composite model derives data from the use of sample indicator, for every ward. 
Table 2: Values of $\phi$ for the wards of Calabar South Local Government Area. [3]

\begin{tabular}{|l|l|l|l|l|l|}
\hline WARDS & DOM. & IND. & PUB. & AGRIC. & REC. \\
\hline Ward 1 & 0.25 & 1.05 & 0.34 & 0.00 & 0.29 \\
\hline Ward 2 & 0.35 & 0.62 & 0.00 & 0.53 & 0.19 \\
\hline Ward 3 & 0.69 & 0.74 & 0.16 & 0.00 & 0.58 \\
\hline Ward 4 & 0.49 & 1.54 & 0.00 & 0.00 & 0.49 \\
\hline Ward 5 & 0.34 & 0.82 & 0.00 & 0.00 & 0.35 \\
\hline Ward 6 & 0.55 & 0.74 & 0.00 & 0.62 & 0.39 \\
\hline Ward 7 & 0.70 & 0.93 & 0.49 & 0.00 & 0.51 \\
\hline Ward 8 & 0.50 & 0.65 & 0.00 & 0.00 & 0.48 \\
\hline Ward 9 & 0.75 & 0.92 & 0.19 & 0.00 & 0.65 \\
\hline Ward 10 & 0.53 & 0.91 & 0.00 & 0.00 & 0.31 \\
\hline Ward 11 & 0.62 & 0.78 & 0.00 & 0.00 & 0.23 \\
\hline Ward 12 & 1.00 & 1.00 & 1.00 & 1.00 & 1.00 \\
\hline Total & 6.77 & 1.07 & 2.08 & 2.15 & 5.47 \\
\hline
\end{tabular}

\section{Result And Discussion}

\section{CASE OF STUDY OF WARD 12 IN CALABAR SOUTH LOCAL GOVERNMENT AREA}

Ward 12 has been selected as a case study because it is a reflective of the situation in the Local Government.

Base on the case study, ward 12 had a total electricity demand of about $55.35 \mathrm{mw}$ consisting of

$\begin{array}{lll}\text { Domestic } & = & 32.04 \\ \text { Industrial } & = & 10.5 \\ \text { Public }= & 2.87 & \\ \text { Agriculture } & = & 1.2 \\ \text { Recreational } & = & 8.78\end{array}$

Using the $\phi$ model which is considered most cost effective among the three models discoursed previously, the total electricity demand for all wards of Calabar South Local Government Area and a sectional breakdown of the electricity demand by wards will be analyzed in the Table 3 .

From the Table 2, the study has revealed that the total electricity demand of Calabar South Local Government is about $55.36 \mathrm{mw}$.

\section{CALABAR SOUTH ELECTRICITY DEMAND PROJECTION}

From the study, Calabar South Local Government Area have a total Domestic demand of 32.04mw, industrial demand of $10.5 \mathrm{mw}$, public demand $2.87 \mathrm{mw}$, Agricultural demand $1.2 \mathrm{mw}$, Recreational demand 2.78 totaling 55.36mw. Therefore in projecting the electricity demand in Calabar South Local Government Area with respect to the developed model it is important to project the population of the Local Government, number if industries, number if agricultural forms, number of public sectors and the number of recreational sectors according to the developed models.

Table 3: Total Electricity Demand of Calabar South Local Government Area by Wards (MW)

\begin{tabular}{|l|l|l|l|l|l|l|}
\hline Wards & Dom. & Ind. & Pub. & Agric. & Rec. & Total \\
\hline 1 & 1.18 & 1.03 & 0.32 & 0 & 0.47 & 3.00 \\
\hline 2 & 1.67 & 0.61 & 0 & 0.53 & 0.31 & 3.17 \\
\hline 3 & 3.25 & 0.73 & 0.15 & 0 & 0.94 & 5.07 \\
\hline 4 & 2.3 & 1.51 & 0 & 0 & 0.78 & 4.59 \\
\hline 5 & 1.62 & 0.81 & 0 & 0 & 0.56 & 2.99 \\
\hline 6 & 2.62 & 0.73 & 0 & 0.62 & 0.62 & 4.59 \\
\hline 7 & 3.3 & 0.91 & 0.46 & 0 & 0.82 & 5.49 \\
\hline 8 & 2.36 & 0.64 & 0 & 0 & 0.77 & 3.77 \\
\hline 9 & 3.56 & 0.90 & 1.01 & 0 & 1.04 & 6.51 \\
\hline 10 & 2.52 & 0.89 & 0 & 0 & 0.50 & 3.91 \\
\hline 11 & 2.92 & 0.76 & 0 & 0 & 0.37 & 4.05 \\
\hline 12 & 4.74 & 0.98 & 0.93 & 0 & 1.6 & 8.25 \\
\hline Total & 32.04 & 10.5 & 2.87 & 1.2 & 8.78 & 55.35 \\
\hline
\end{tabular}


According to available information, Nigerian population growth rate as at 2011 was $1.7 \%$, with industrial growth rate at $4 \%$, literacy rate was $20 \%$, and commercial farm growth rate was $5 \%$ and $20 \%$ for recreation.

Therefore, to project electricity demand in the Local Government for the next 5-20 years will be achieve with the relation below:

\section{Next 5years}

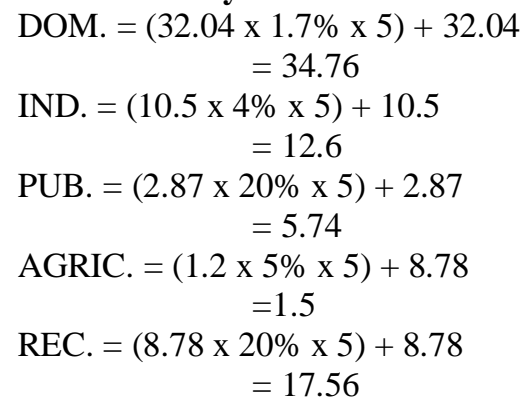

\section{Next 10years}

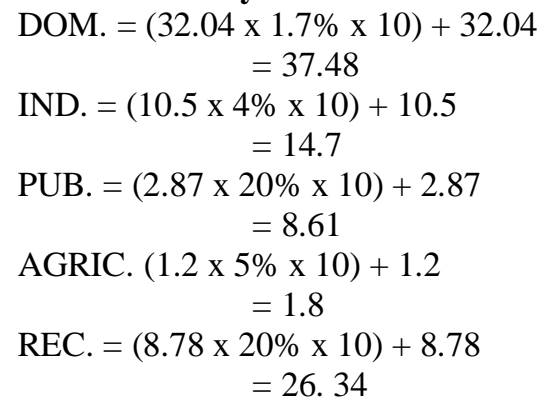

\section{Next 15years}

DOM. $=(32.04 \times 1.7 \% \times 15)+32.04$

$$
=40.21
$$

IND. $=(10.5 \times 4 \% \times 15)+10.5$

$$
=16.8
$$

PUB. $=(2.87 \times 20 \% \times 15)+2.87$

$=11.48$

AGRIC. $=(1.2 \times 5 \% \times 15)+8.78$

$=35.12$

\section{Next 20years}

DOM. $=(32.04 \times 1.7 \% \times 20)+32.04$ $=42.93$

IND. $=(10.5 \times 4 \% \times 20)+10.5$

$$
=18.9
$$

PUB. $=(2.87 \times 20 \% \times 20)+2.87$

$$
=14.35
$$

AGRIC. $=(1.2 \times 5 \% \times 20)+1.2$

$$
=2.4
$$

REC. $=(8.78 \times 20 \% \times 20)+8.78$

$$
=43.9
$$

Table: 4 Total Electricity Demand Projections (MW)

\begin{tabular}{|l|l|l|l|l|}
\hline Sector/Year & 2017 & 2022 & 2027 & 2032 \\
\hline Domestic & 34.76 & 37.48 & 40.21 & 42.93 \\
\hline Industrial & 12.6 & 14.7 & 16.8 & 18.9 \\
\hline Public & 5.74 & 8.61 & 11.48 & 14.35 \\
\hline Agricultural & 1.5 & 1.8 & 2.1 & 2.4 \\
\hline Recreational & 17.56 & 26.34 & 35.12 & 43.9 \\
\hline Total & 72.16 & 88.93 & 105.71 & 122.48 \\
\hline
\end{tabular}


In Table 4, the total electricity demand projection in 2017 is $27.16 \mathrm{mw}$, with domestic demand having the highest value of $34.76 \mathrm{mw}$ followed by recreational demand with 17.56. In 2032 the demand for recreational centers will rise above every other sector because of the rapid development of the state.

Figure 1 is the electricity demand projection of the Local Government as at 2017, 2022, 2027 and 2032 respectively.

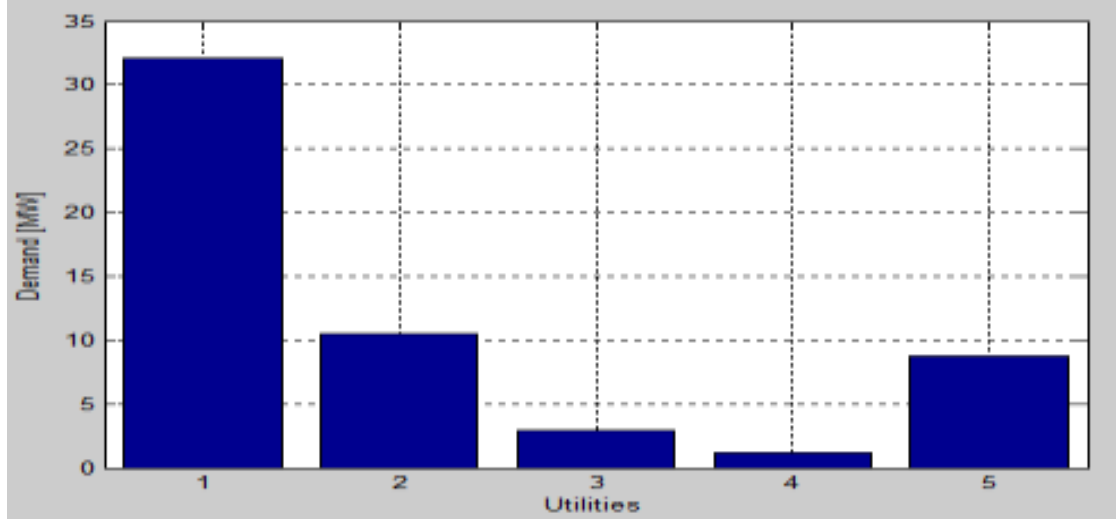

Fig: 1 Bar chart showing the electricity demand in Calabar south

Figure 2 is a graph showing the projected electricity demand from $2017-2032$.

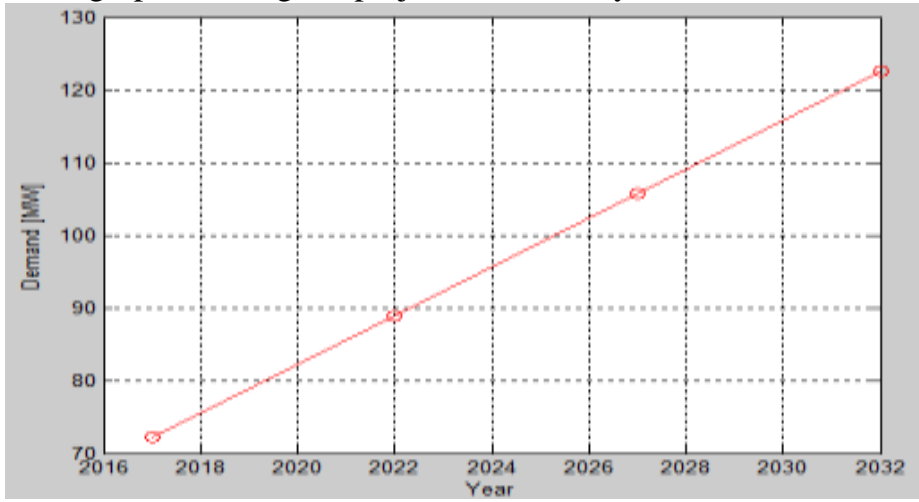

Total Electricity Demand Projection (MW).

Graph showing the projected electricity demand from 2017 - 2032.

$\begin{array}{lll}2017 & - & 72.16 \\ 2022 & - & 88.93 \\ 2027 & - & 105.71 \\ 2032 & - & 122.48\end{array}$

\section{COST OF USING GENERATORS TO GENERATE ELECTRICITY}

The cost of generating electricity includes initial capital return on investment as well as the cost of continuous operation, fuel and maintenance. In order to get the cost of generating electricity using generator in ward 12, the relation below is applied.

Production cost $=$ cost of fuel + operational cost to get the cost of the fuel the relation is given below .

Cost of fuel consumed $=$ quantity of fuel consumed $\mathrm{x}$ price of fuel.

Assuming a company uses 2000 liters of fuel per day electricity at $\$ 97$ per liter.

The cost of fuel $=2000 \mathrm{x} \$ 97=\$ 194.000$ per day.

Therefore in a month, cost of fuel $=\$ 194.000 \times 31$ days $=\$ 60.14000$.

The operation cost $=$ cost of maintenance + cost of hiring a personnel.

Assuming the company paid 100, 000 per month for maintenance and servicing and pays the personnel $\$ 50,000$ per month as salary. 
Therefore the operational cost $=\$ 100,000+N 50,000$

Therefore the cost of product $\$ 6014,000+\$ 150,000=\$ 6164.000$

Therefore the cost of production will be $=\mathrm{N} 6164000$ per company in wards of the local government

Therefore the cost of production of electricity will be $616400 \mathrm{x}$ numbers of companies.

\section{ENVIRONMENTAL IMPACT OF USING GENERATORS TO GENERATE ELECTRICITY IN CALABAR SOUTH LOCAL GOVERNMENT AREA}

Electricity generation accounts for nearly 40 percent of emission, fossil fuel combustion for electricity power generation is responsible for $60 \%$ of all emission of sulfur dioxide the main component of acid rain.

The Emission that results from fossil fuel burning constitute a significant repository of carbon buried deed under the ground, burning them results in the conversion of the carbon to carbon dioxide, which is then released into the atmosphere, the estimated CDs emission from burning in an increase in the earth level of atmosphere carbon dioxides, which enhances the greenhouse effect and contributes to global warming and also pollute the atmosphere, therefore the air around the environment is unsafe to use for the purpose of breathing.

\section{Conclusion}

The generation capacity of PHCN power station as operated between July and August of 2011 in the county was grossly inadequate. The total installed capacity was about 9,000MW and of which the total demand of Cross River State was about 105MW which constitute $12.23 \%$ of the total demand of $858 \mathrm{mw}$.

It is therefore a happy development that the federal government has taken strong measures to improve electricity supply through encouragement of private investors, like Independent Power Producers (IPPs) and also establishing a program like the National Integrated Power Program (NIPP)

\section{Recommendation}

The model can be readily updated and dynamically applied to account for change in population growth, change in lifestyle of the citizen and increase economic activities such as the establishment of more industries etc.

\section{References}

[1] Adekoya, A. "The Role of Government in Promoting Electricity", Proceeding of the First National Conference on Productivity, National Productivity Centre. Page 56. (1987).

[2]. Oloko, O. "Factors of Electricity Production", Proceeding of a National Conference on Productivity, Edited by Osoba, A.M. Page 7. (1983).

[3] PHCH. "Power sector Report", pp. 43 - 45, (2010).

[4] Aya, Peter O. "The Overview of the state Electrification in Nigeria". Mbendi Journal, Vol. 8, pp. 15 -17, (2008).

[5]. Ibe, D. G. "The overview of Electricity in Nigeria", Nigeria Tribune, pp. 4 - 6, (2010).

[6]. Udo-Aka, U. "Measuring productivity" Issues and Problems in Electricity Production in Nigeria, Proceedings of a National Conference, Edited by Osoba, A.M., Page 75. (1983).

[7] Autor, D. H., Kerr, W. R., and Kugler, A. D. Does Electricity Generation Increase productivity? Evidence from US States. Economic Journal, 117: pp. 189 - 217. (2007).

[8]. Aderoba, A. A. "Strategies for Engineering Development in Nigeria" $24^{\text {th }}$ Inaugural Lecture Federal University of Technology Akure, Nigeria, pp $14-26,(2000)$.

[9]. Ibe, A. O. and Okedu, E. K. "Optimized Electricity Generation in Nigeria", Nigerian Journal of Engineers and Management, Vol. 8, No. 4, pp. 7 - 16, (2009).

[10]. Adbul, A. D. "Electrical Issues and Opinions, NEPA Review". The Nigeria Power system in the 21th Century; NEPA Publication, Nigeria (July - October), pp. $36-42,(2005)$. 